\title{
ИНФОРМАЦИОННЫЙ ПОТЕНЦИАЛ КАК ФАКТОР РАЗВИТИЯ РОССИЙСКОЙ ФЕДЕРАЦИИ
}

\author{
(c) 2021 Абдулганиев Ф.С. \\ доктор экономических наук, доцент \\ Казанский (Приволжский) федеральный университет, Россия, Казань \\ E-mail: Farid.Abdoulganiev@ksu.ru \\ (С) 2021 Орлов И.Ю. \\ кандидат экономических наук, докторант \\ Казанский (Приволжский) федеральный университет, Россия, Казань \\ E-mail:snf079@yandex.ru
}

В статье представлены результаты анализа позиционирования Российской Федерации по индикативным показателям развития информационной экономики в глобальных рейтингах. Отмечено, что результаты методологических разработок на мировом уровне способствуют проведению адекватного сравнительного анализа динамики развития информационной экономики в Российской Федерации и других стран, а также определения ключевых факторов информационного потенциала, обусловливающих формирование стратегических решений, направленных на совершенствование и усиление данного потенциала.

Сделаны выводы о том, что реализация идеи электронного или цифрового правительства является средством повышения качества предоставляемых государственных услуг на основе совершенствования критериев прозрачности, подотчетности и инклюзивности, а также вовлеченности физических лиц, что, в целом, способствует прогрессивному устойчивому социально-экономическому развитию общества.

Значимость электронного правительства повышается в условиях оказания поддержки тем странам, основным направлением прогресса которых является активизация деятельности по достижению Целей в области устойчивого развития, что обусловливает необходимость взаимодействия правительств не только между собой, но и, базируясь на принципах эффективного партнерства, со всеми заинтересованными сторонами, в том числе и технологическими лидерами и представителями малого и среднего бизнеса, и определяет новые «цифровые нормы» реагирования на глобальные вызовы и обеспечении устойчивого социально-экономического развития.

Ключевые слова: электронное правительство, Индекс развития электронных услуг, Индекс телекоммуникационной инфраструктуры, Индекс электронного участия, Индекс услуг, Индекс человеческо20 капитала

Широкомасштабное использование информационно-коммуникативных и интернет-технологий обусловило формирование и глобализацию информационного общества, базирующегося на глубокой трансформации социальной и экономической сфер в цифровой направленности, обеспечивающей ускорение темпов экономического развития, в том числе, и на мировом уровне, повышение производительности труда, формирование новых экономических и производственных сфер, а также достижение устойчивого экономического роста [5]. Необходимо отметить, что в сложившихся условиях цифровизация социальной сферы обусловливает усиление инклюзивизации за счет повышения скорости и эффективности коммуникаций различных сообществ, обмена информацией, результатов материальной и нематериальной деятельности.

Отличительной особенностью социально-экономического развития в настоящее время является не только полномасштабное применение искусственного интеллекта, прогнозной аналитики, аддитивных технологий, интернет-ресурсов, но и активизация аккумулированной диджитальной информации о функционировании экономических субъектов в условиях неравномерного развития отдельных традиционных экономических сфер, взаимопроникновения смежных отраслей, формирования ранее не существовавших областей экономической деятельности, образования принципиально иных бизнес-моделей.

Процессинг информационной трансформа- 
ции характеризуется высокой сложностью и многомерностью в условиях воздействия множества разнообразных факторов, дифференциация которых, их ранжирование и измерение способствуют актуализации стратегических решений, а также адекватности планирования деятельности в соответствие с ключевыми направлениями и осуществлению корректирующего воздействия с помощью функции обратной связи.

Используемые в мировой практике методики измерения хода развития и применения информационно-коммуникационных технологий не всегда являются актуальными по отношению к динамично модифицируемым новейшим технологиям и процессам экономического развития, что обусловливает необходимость модернизации существующих международных стандартов мониторинга и процессинга измерения различных аспектов информационной экономики.

Исследуем позиционирование Российской Федерации по индикативным показателям развития информационной экономики в глобальных рейтингах.

В соответствии с проведенными расчетами обновляемого один раз в течение двух лет индекса EDGI [6], по результатам 2020 года Российской Федерации принадлежит 36-е место (рисунок 1) с показателем 0,8274, что характеризуется как «очень высокий» уровень развития электронного правительства (EDGI более 0,75 до 1,0).

Исследуемая динамика для Российской Федерации за период 2016-2020 годов демонстрирует первоначальный значительный прирост, а затем снижение Индекса услуг, предоставляемых онлайн (0,7319 в 2016 году, 0,9167 в 2018 году, и 0,8176 в 2020 году), а также стабильный прирост для Индекса телекоммуникационной инфраструктуры $(0,6091$ в 2016 году, 0,6219 в 2018 году и 0,7723 в 2020 году) и Индекса человеческого капитала (0,8233 в 2016 году, 0,8522 в 2018 году и 0,8833 в 2020 году). Следовательно, можно резюмировать, что понижение позиции Российской Федерации в данном рейтинге в 2020 году по сравнению с 2018 годом обусловлено достаточно резким снижением развития государственных сервисов, предоставляемых в режиме онлайн.

За период с 2012 года наблюдалась высокая положительная динамика Индекса услуг для Российской Федерации, что обуславливалось как переводом услуг в электронную форму, так и созданием единого портала государственных и муниципальных услуг, а также раскрытием информации о деятельности органов власти на официальных сайтах, а в дальнейшем получило развитие за счет увеличения количества предоставляемых онлайн услуг и активизации двустороннего взаимодействия с гражданами.

Начиная с 2014 года произошли значительные изменения в обследовании официальных сайтов государственных сервисов. Новая методика ООН по вычислению данного индекса включает в себя более новые и расширенные критерии, позволяющие оценить современные тенденции развития электронных правительств по показателям многоканальности, мобильности, ориентированности на потребителя, соответствия предоставляемых услуг жизненным ситуациям, по широте инструментария по вовлечению граждан в управленческий процессуал, по степени реализованности подхода целостности правительства и пр. В Индексе услуг, предоставляемых онлайн за 2014 год Российской Федерацией по показателям развития начальных и продвинутых

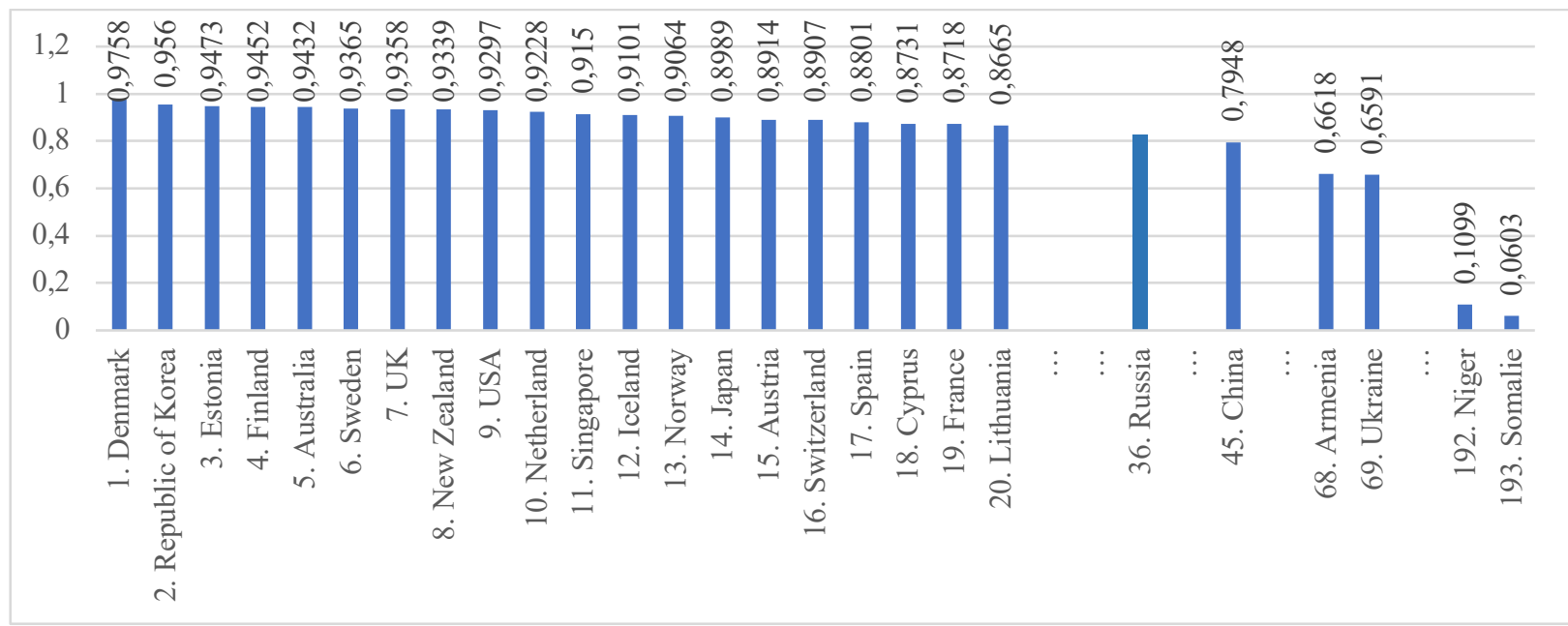

Puc. 1. Позиционирование Российской Федерации в рейтинге развития электронного правительства за 2020 г. 
информационных сервисов, а также транзакционных и сетевых/интеграционных сервисов было реализовано соответственно $50,8 \%$ и $34,9 \%$ от максимально возможной величины критериев, что также способствовало значительному приросту рейтинга (27-е место из 27 стран-лидеров), однако к 2016 году в связи с активной реализацией другими странами требований к правительственным онлайн услугам, Российская Федерация позиционировалась на 38 месте.

Очередная корректировка методики оценки официальных сайтов в целях совершенствования расчетов Индекса развития электронного правительства в 2018 году, направленная на расширение числа показателей, отражающих «цели устойчивого развития» в интерпретации Организации объединенных наций, не оказала особого влияния на основные параметры оценки, включая введенные в 2014 году. Необходимо отметить, что позитивная направленность динамики показателей Российской Федерации за период 2016-2018 гг (рисунок 2) обусловлена целенаправленностью воздействия на них Министерством коммуникации и связи РФ, заключающейся в разработке рекомендаций и Единых функционально-технических требований к порталам Правительства Российской Федерации и интернет-сайтам министерств, на основе современных тенденций развития электронных правительств и критериев оценки Организации объединенных наций.

Необходимо отметить значительную динамику для субиндекса Индекса телекоммуникационной инфраструктуры (TII) за период 20182020гг [4]. Детализируем данный субиндекс покомпонентно и представим на рис. 3.

При выявленной положительной динамике величины Индекса телекоммуникационной инфраструктуры за исследуемый период необходимо отметить снижение числа абонентов мобильной связи на 100 жителей Российской Федерации, что может быть обусловлено активизацией общения в сети интернет и социальных сетях, что практически нивелирует необходимость непосредственного общения. Кроме того, сокращается количество применяемых сим-карт на одного абонента, особенно среди молодежи.

Несмотря на недифференцированность подхода к исследованию развития информационно-коммуникационных технологий в Российской Федерации с позиции практически исключительно национальной безопасности, необходимо оценивать данное направление с чисто экономических позиций, что обусловлено значительным уровнем влияния информации, в целом, и информационной инфраструктуры, в частности, на мировое экономическое развитие.

В соответствие с оценками Boston consulting group, установлено существенное превышение воздействия на экономическое развитие интернет-технологий по сравнению с влиянием иных других технологий [10], определяя необходимость развития сектора информационных технологий как важнейшего условия экономического роста. По мнению К. Шваба в настоящее время осуществляется четвертая промышленная революция, называемая иначе «промышленная революция 4.0» или «промышленность 4.0» [9], представляющая собой синергию потен-

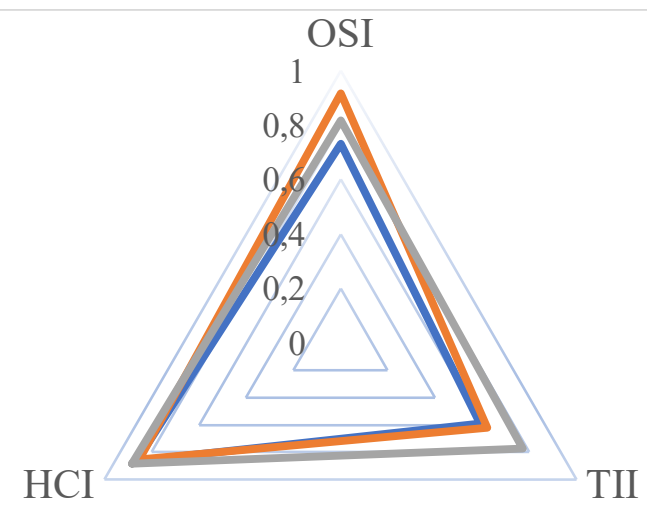

$-2016$

$-2018$

$-2020$

Puc. 2. Покомпонентная динамика Индекса развития электронных услуг (E-Government Development Index, EDGI) за период 2016-2020гг [2] 


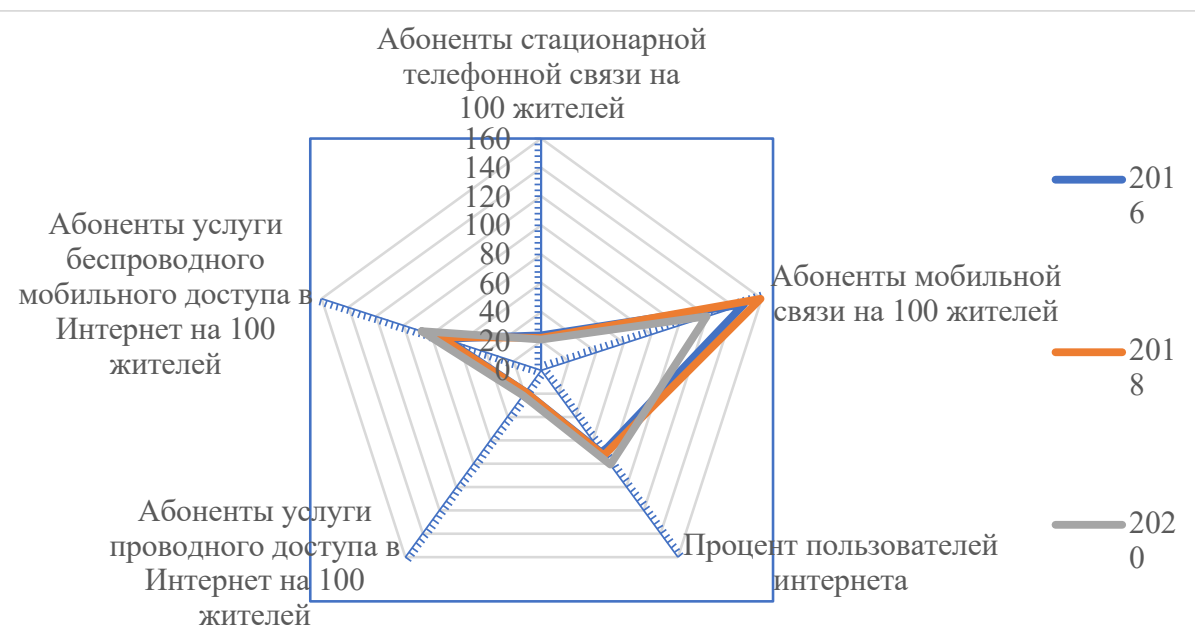

Puc. 3. Структуризация Индекса телекоммуникационной инфраструктуры (TII) за период 2018-2020гг [2]

циалов информационных технологий, промышленного производства, интернета вещей и интернета услуг. В условиях интернет-экономики обеспечивается прирост глобального валового внутреннего продукта порядка 21\% за последние пять лет [4], что обусловливает достаточно пристальное внимание всех субъектов хозяйствования к развитию интернет-технологий во всех сферах экономической деятельности.

Необходимо отметить, что доминирование и достаточно сильные позиции российских компаний, функционирующих в сфере интернет-услуг или информационных технологий, среди стран СНГ не является приоритезирующим влиянием по численности пользователей, показателям капитализации, воздействию на определение рыночных правил по отношению к таким крупным западным компаниям как, к примеру, Google, Facebook и др. Следовательно, Российская Федерация в условиях функционирования в информационной или интернет-экономике представляет собой лишь региональный поляризационный центр, не обладающий глобальной величиной потенциала и ресурсов.

По показателю Индекса электронного участия (E-Participation Index), формируемого на основе показателей Индекса услуг, предоставляемых онлайн, демонстрирующих уровень электронного информирования граждан, их консультирование и участие в принятии решений [8], Российской Федерации в 2020 году принадлежит 81,76\% (в 2018 году - 92,39\%, в 2016 году 74,99\%), что соответствует 29 месту (в 2018 году соответственно - 23 место, в 2016 году - 32 место). Уровень Индекса электронного участия Российской Федерации за период 2016-2018 гг. демонстрирует нестабильную динамику, соответствующую Индексу EDGI в целом. Динамика как EPI, так и этапов его реализации в исследуемом периоде представлена на рис. 4.

Однако, необходимо исследовать результативность представления Правительствами онлайн-услуг на основе двадцати типов транзакций, реализуемых в виртуальном пространстве, и их доступность на правительственных порталах Российской Федерации в процентном соотношении от максимально возможного числа, что представлено на рис. 5. в виде структуры Индекса услуг, предоставляемых онлайн (OSI) за 2020 год.

В соответствии с представленными данными наблюдается значительный рост практически всех компонентов Индекса услуг, предоставляемых онлайн, в Российской Федерации в 2020 году, что обусловливается мероприятиями по сдерживанию пандемии новой коронавирусной инфекции COVID-19, и переводом множества предоставляемых оффлайн услуг в режим «онлайн». При этом падение продемонстрировали компоненты «Регистрация компаний», что потенцируется снижением коммерческой активности и закрытием организаций, а также «Заявка на вакансии в правительстве онлайн», определяемые возможным сокращением количества вакансий в период дистанционной работы правительственных сфер. Необходимо отметить, что, в соответствии с исследованием ООН, полный спектр данных онлайн услуг предостав- 


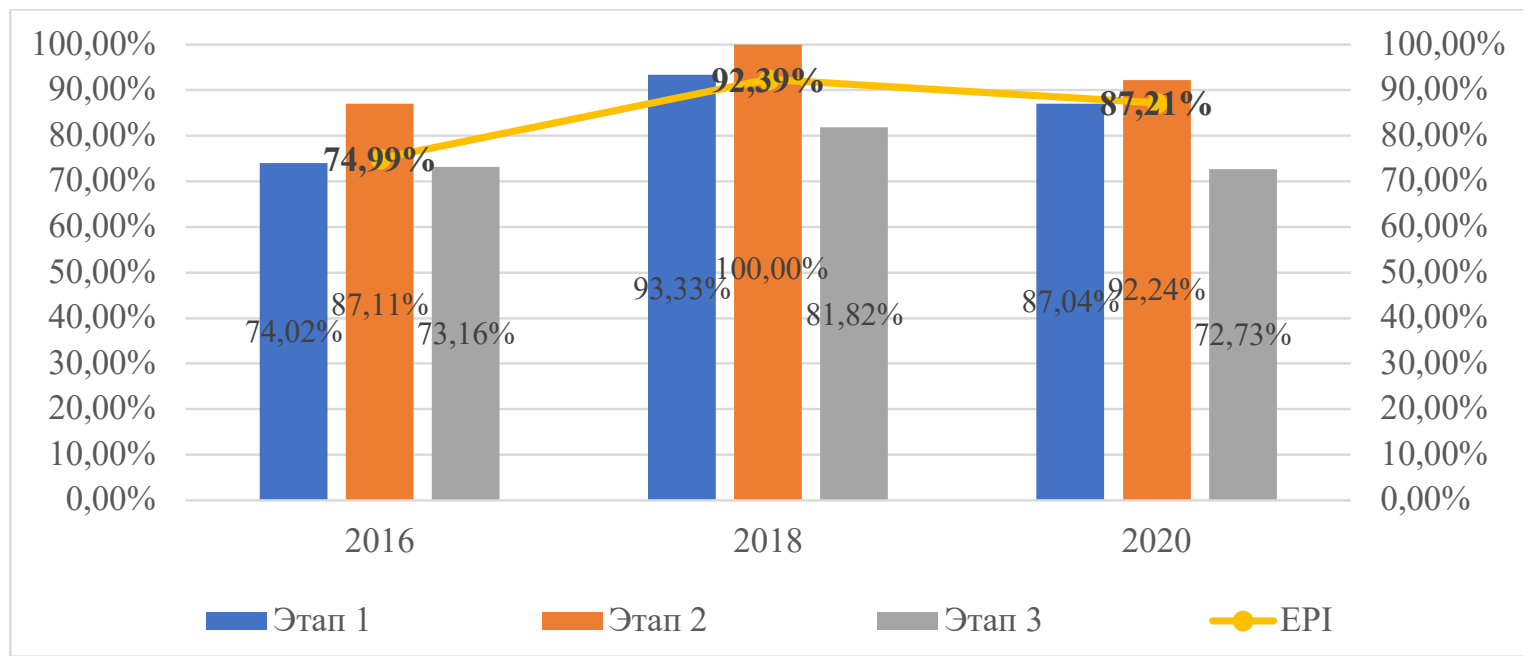

Puc. 4. Динамика Индекса электронного участия (EPI) и этапов его реализации в Российской Федерации за период 2016-2020 гг.

ляют более $70 \%$ европейских стран, включая Российскую Федерацию, 9\% стран Африки, 13\% стран Океании, 21\% стран Северной и Южной Америки и $36 \%$ азиатских стран.

В соответствии с проведенными Организацией объединенных наций исследованиями, Индекс человеческого потенциала составляет 0,68, что представляет собой возможность достижения к восемнадцатилетию рожденным в настоящее время в Российской Федерации детям 68\% от максимальных объемов полного образования и абсолютного здоровья. Необходимо отметить, что за период 2010-2020 гг. изменение данного индекса для Российской Федерации составило 0,08 пП., продемонстрировав рост с величины 0,60 в 2010 году до 0,68 в 2020 году. Данный показатель является более низким по сравнению со средними по регионам Европы и Центральной Азии, однако выводит Российскую Федерацию на третье место среди стран с соответствующим уровнем доходов.

Необходимо отметить, что среди стран региона Европы и Центральной Азии Российской Федерации принадлежит достаточно высокая оценка за показатели образования населения и одна из самых низких оценок критериев здоровья населения.

При этом показатель Индекса человеческого капитала (HCI [7]) в соответствии с данными Обзоров ООН по электронному правительству в Российской Федерации в 2020 году составлял 0,8833 , что обусловлено набором показателей для формирования данного Индекса, структура и динамика которого представлены на рис. 6 .

В связи с отсутствием в данной методике по- казателей здоровья детей и взрослых за 2020 год наблюдается значительный прирост НCI за 2020 год. В связи с мероприятиями по сдерживанию пандемии новой коронавирусной инфекции COVID-19 показатели как детского, так и взрослого здоровья не могли быть оценены адекватно. При этом, необходимо отметить наращивание показателей грамотности взрослых и валового коэффициента охвата обучением.

Таким образом, необходимо отметить важнейшую роль информационно-коммуникационных технологий в поддержании функционирования социально-экономического пространства и безопасности человека в период пандемии COVID-19. С помощью цифровых технологий электронных правительств, позволяющих обмениваться информацией и оказывать услуги в режиме онлайн, обеспечивалась взаимосвязь как между физическими субъектами, так и государственными структурами и правительствами, что, основываясь на аналитических и фактических данных, способствует быстрому принятию политических решений в режиме реального времени, расширению потенциала местных органов власти в целях повышения координированности взаимодействий и направленности предоставляемых услуг. Реализация идеи электронного или цифрового правительства является не самоцелью, а средством повышения качества предоставляемых государственных услуг на основе совершенствования критериев прозрачности, подотчетности и инклюзивности, а также вовлеченности физических лиц, что, в целом, способствует прогрессивному устойчивому социально-экономическому развитию общества. 


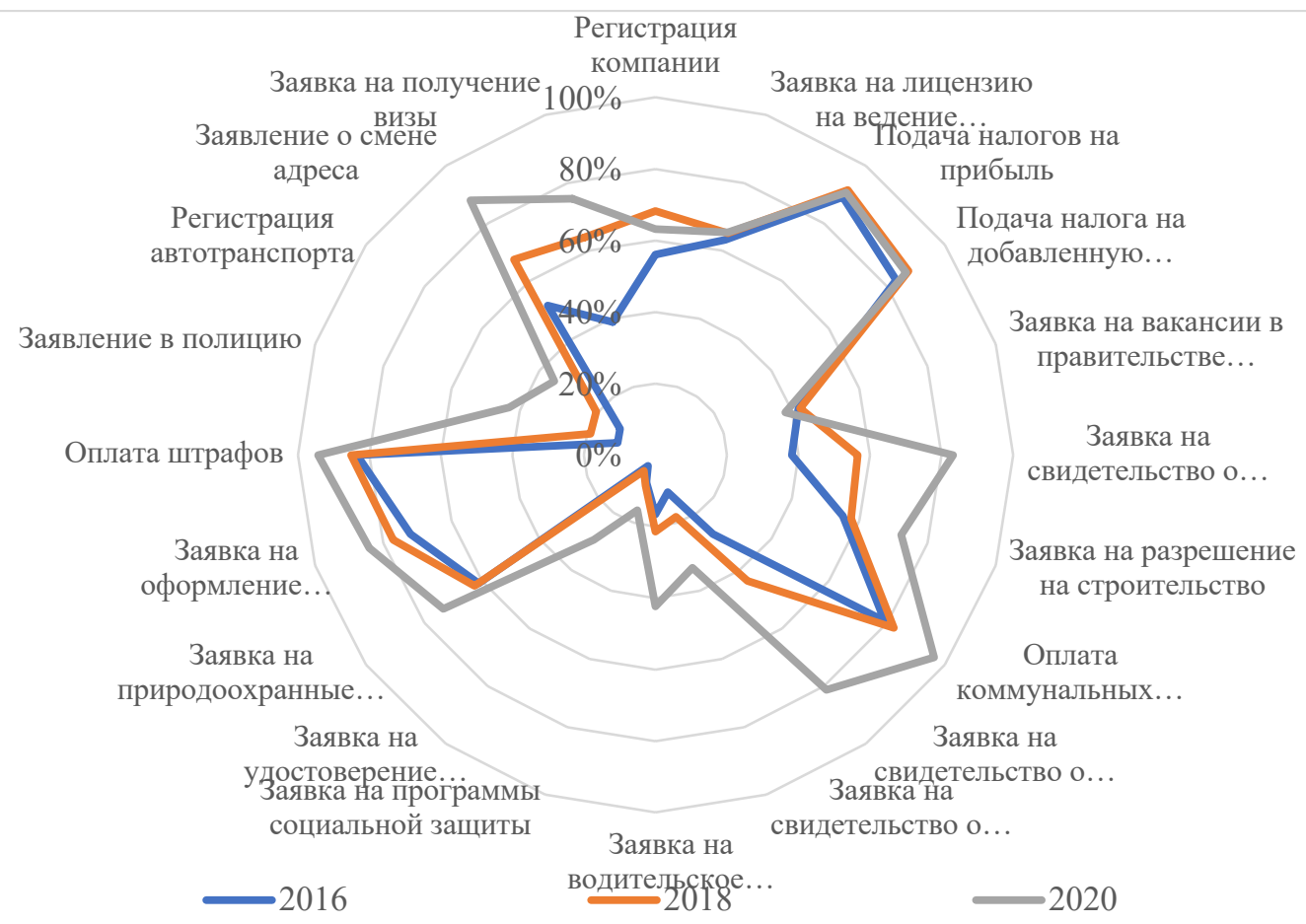

Puc. 5. Динамика компонентов Индекса услуг, предоставляемых онлайн (OSI) в Российской Федерации за период 2016-2020 гг.



Puc. 6. Структуризация и динамика Индекса человеческого капитала (HCI) в Российской Федерации за период 2016-2020 гг. 


\section{Библиографический список}

1. Коростышевская Е.М., Миэринь Л.А., Фахрутдинова Е.В. Инновационная система ЕС и место России в европейском инновационном пространстве// Современное искусство экономики. 2015. № 2 (20). С. $59-67$.

2. Обзор ООН по электронному правительству за 2016-2020 гг. [Электронный ресурс] Режим доступа: http:// workspace.unpan.org/sites/Internet/Documents/UNPAN97453.pdf.

3. Фахрутдинова Е.В. Роль социальной сферы и социальной политики в обеспечении устойчивого социально-экономического развития страны// Экономические науки. 2009. № 57. С. 7-11.

4. Garofalo A., Agovino M., Aldieri L., Vinci C.P. Quality and Quantity in the Innovation Process of Firms: A Statistical Approach // Quality \& Quantity, 2017, 51 (4)

5. G20 Digital Economy Development and Cooperation Initiative. [Электронный ресурс] Режим доступа: http:// www.g20chn.com: 12.08.2021.

6. Ivanova M., Degtereva V., Lukin G. Evaluation of Digital Transformation of Government: Russian and international systems of indicators // PervasiveHealth: Pervasive Computing Technologies for Healthcare, 2019.

7. Kraay A. The world bank human capital index: A guide // World Bank Research Observerthis, 2019,34 (1), pp. 1-33.

8. Pirannejad A., Janssen M., Rezaei J. Towards a balanced E-Participation Index: Integrating government and society perspectives // Government Information Quarterlythis link is disabled, 2019, 36 (4).

9. Schwab K. The fourth industrial revolution //Foreign Affairs. 2015.- T. 12.

10. The internet economy in the G20 // BCG Report, 2012. [Электронный ресурс] Режим доступа: https://www.bcg. com/documents/file100409.pdf Дата обращения: 16.08.2021. 